\title{
(1) в \\ Can a theoretical framework help to embed alcohol screening and brief interventions in an endoscopy day-unit?
}

\author{
G O'Neill, ${ }^{1}$ S Masson, ${ }^{2,3}$ L Bewick, $^{2} \mathrm{~J} \mathrm{Doyle}^{2}{ }^{2} \mathrm{R}$ McGovern, ${ }^{1}$ E Stoker, ${ }^{2}$ \\ H Wright, ${ }^{2}$ D Newbury-Birch ${ }^{4}$
}

${ }^{1}$ Institute of Health \& Society, Newcastle University, Newcastle Upon Tyne, UK

${ }^{2}$ The Newcastle Upon Tyne Hospitals NHS Foundation Trust, Newcastle Upon Tyne, UK ${ }^{3}$ Institute of Cellular Medicine, Newcastle University, Newcastle Upon Tyne, UK

${ }^{4}$ School of Health \& Social Care, Teesside University, Middlesbrough, UK

\section{Correspondence to} Professor Dorothy NewburyBirch, School of Health \& Social Care, Teesside University, Middlesbrough, TS1 3BA, UK; d.newbury-birch@tees.ac.uk

Received 20 August 2014 Accepted 4 March 2015 Published Online First 24 March 2015

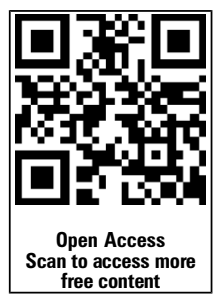

CrossMark

To cite: O'Neill G, Masson S, Bewick $L$, et al. Frontline Gastroenterology 2016;7: 47-53.

\begin{abstract}
Introduction and aims The National Institute for Health Care and Excellence recommend that alcohol screening and brief intervention (ASBI) should be routinely implemented in secondary care. This study used theoretical frameworks to understand how health professionals can be supported to adapt their behaviour and clinical practice.
\end{abstract}

Design and methods Staff training and support was conducted using theoretical frameworks.

A 12-week study, delivering ASBI was carried out as part of routine practice in an endoscopy dayunit. Anonymised patient data were collected using the Alcohol Use Disorders Identification Tool (AUDIT) and whether patients received a brief intervention. Staff completed the Shortened Alcohol and Alcohol Problems Perceptions Questionnaire at three time points and took part in a focus group both pre and post study.

Results For staff, levels or role adequacy, role legitimacy, motivation to discuss alcohol, security in their role, job satisfaction and commitment to working with patients who drink increased during the time of the study. 1598 individual patients were seen in the department in the timeframe. Of these, 1180 patients were approached $(74 \%) ; 18 \%(n=207)$ of patients were AUDIT positive.

Discussion This study has shown that it is possible to reach a high number of patients in a busy hospital out-patient department and deliver ASBI by working with staff using theoretical frameworks for training. Embedding evidencebased public health interventions into routine clinical environments is complex. The social system in which professionals operate requires consideration alongside individual professionals' real and perceived barriers and facilitators to change.

\section{BACKGROUND}

In the UK, alcohol is responsible for $7 \%$ of all hospital admissions, costing the National Health Service (NHS) around $£ 2.7$ billion per year. ${ }^{1}$ Individuals in North-East England make up the highest levels of hazardous and harmful (risky) drinkers in England (32\%). ${ }^{2}$ Risky drinking is associated with a large number of chronic diseases and injury ${ }^{3}$ as well as increasing the risk of in-hospital deaths for surgical patients. ${ }^{4}$ Reducing alcoholrelated harm is therefore a governmental priority. 56

Screening the adult population for risky drinking and providing feedback and brief advice results in a reduction in the amount consumed in one in seven people. ${ }^{78}$ Brief intervention is a secondary prevention activity aimed at individuals who are drinking excessively or in a drinking pattern that is likely to be harmful, with the aim of helping people to change their drinking behaviour to promote health but they vary in the precise means by which this is achieved. ${ }^{9}$ They can be implemented by a range of practitioners in a wide variety of settings. ${ }^{10}$

The evidence demonstrates the efficacy of alcohol screening and brief intervention (ASBI) in healthcare settings in reducing alcohol consumption, most notably within the primary-care setting ${ }^{11}$ as well as some evidence of short-term efficacy in the inpatient setting. ${ }^{12} 13$ The strength of evidence has resulted in National Institute of Health and Care Excellence (NICE) public health guidance recommending that NHS professionals routinely screen patients for alcohol consumption as part 
of everyday healthcare within a variety of settings. ${ }^{14}$ However, the evidence for the efficacy of ASBI for dependent drinkers is inconsistent with one review finding that the benefits cannot be extended to very heavy and dependent drinkers. ${ }^{15}$

However, routine practice of ASBI has proven difficult. ${ }^{16}$ Reasons for this include alcohol being considered to be a contentious topic to discuss with patients. ${ }^{17}{ }^{18}$ Staff being too busy, lack of motivation and lack of adequate training are also seen as barriers, ${ }^{16} 19$ as well as screening tools not being integrated into assessment tools. ${ }^{20} 21$

As there is a well-documented association between alcohol and gastrointestinal disease, including liver disease, gastro-oesophageal reflux and cancers of the bowel, oesophagus and larynx, ${ }^{16-22}$ gastrointestinal departments were identified as a priority department by the local hospital. ${ }^{14}$

We report the results of a 12-week study within an endoscopy day-unit in a university teaching hospital in North-East England. The aim of this study was to evaluate whether ASBI can be implemented into a busy hospital department as part of routine clinical practice.

\section{METHODS}

\section{Theoretical framework}

Normalisation Process Theory (NPT) ${ }^{22}$ is concerned with the social organisation of the work (implementation); of making practices routine elements of everyday life (embedding) and of sustaining embedded practices in their social contexts (integration)' (May 2009 p.538). This organisational level appreciation of how to implement new evidence-based interventions is essential when the aim is for whole system change within a department of a hospital. The theoretical domains framework (TDF) ${ }^{23} 24$ was designed to simplify and integrate a plethora of behaviour change theories making theory more accessible. The 14 domains of $\mathrm{TDF}^{23}$ provide a framework encapsulating the main components of behaviour change theory. Experts in the field have acknowledged that not all 14 domains need to be adhered to in any one intervention. ${ }^{23}$ NPT and TDF are the two complementary theories used to inform this study. NPT ensures that the social system is considered while TDF emphasises individual influences on behaviour.

The theoretical frameworks were used to understand how health professionals can be supported to adapt their behaviour and clinical practice which is a fundamental component to the implementation of any new evidence-based intervention. ${ }^{25}$ We involved local opinion leaders through the development of a steering group that oversaw the project. Education meetings (staff training) were delivered in the form of $1 \mathrm{~h}$ face-to-face training sessions for nurses as well as recommending follow-up e-learning. ${ }^{26}$ Tailored interventions tools and training were provided using bespoke resources specifically relevant to endoscopy. ${ }^{27}$ Education leaflets were incorporated into training packs and provided as patient resources. Finally, audit and feedback were an essential component to implementation to assess whether nurses had successfully integrated ASBI into routine practice. ${ }^{28}$ We included an opportunity for weekly feedback with staff on progress and issues arising.

\section{Setting, participants and duration}

The study was conducted in an endoscopy day-unit within a large inner-city hospital in a North-East England hospital run by a Foundation Trust between April and July 2013. Recommendations from the research were to be considered by the hospital Public Health Trust Group.

There were 18 nurses who staffed the endoscopy day-unit during the study. The patient group comprised adults (aged $\geq 18$ years) with gastrointestinal symptoms requiring out-patient endoscopy treatment.

\section{Governance, accountability and ethics}

The protocol for the study was reviewed by the hospital trust research and development department and granted approval as an evaluation. Governance mechanisms were established through approval from the hospital trust senior management group and a multidisciplinary steering group provided an overview and scrutiny role.

\section{Screening and intervention}

The tools used in this present study were adapted from the Screening and Brief Intervention Programmes (SIPS) studies of an ASBI programme of research. ${ }^{7}{ }^{29}$ Patients self-completed the Alcohol Use Disorders Identification Tool (AUDIT) questionnaire in the waiting area prior to their general assessment. During the shadowing of the patient pathway by Gillian O'Neill, the patient assessment was observed to be completed in approximately $7 \mathrm{~min}$. Patients received their AUDIT score, feedback and brief intervention within this $7 \mathrm{~min}$ consultation. The literature informed the feedback and intervention delivered. ${ }^{3729}$ Score 0-7: patients received personalised feedback on the score and positive reinforcement. Score 8-15: patients received 5-10 min of personalised feedback and brief advice in the form of a bespoke brief advice sheet. Nurses provided patients with feedback on their screening outcome plus 5 min of structured personalised brief advice based on the 'SIPS' simple structured advice tool ${ }^{729}$ developed from the UK version of the Drink-Less brief intervention programme. ${ }^{30}$ In addition to providing specific details about the health and social consequences of risky drinking, patients were shown a gender-specific graph which indicated that their drinking exceeded most of the population and a list of benefits that would result from reduced drinking. Patients were then taken through a menu of 
techniques to help reduce drinking and asked to consider a personal target for an achievable reduction.

Patients were given a Department of Health Change for Life leaflet 'Don't let drink sneak up on you'. These leaflets are freely available online in the UK and give advice on drinking alcohol and strategies for change. Patients with a score of $\geq 16$ were given the same 5-min intervention as those scoring 8-15 received. In addition, patients received information on local alcohol services in the form of an alcohol services signposting sticker being added to the back of the Change for Life leaflet. This sticker encouraged patients to contact local alcohol services and contact information related to them was given. Nurses then documented what intervention they had administered on the reverse of the AUDIT questionnaire along with anonymous patient demographic data (age, sex, ethnicity and reason for appointment). The completed documents were reviewed to ascertain if the appropriate interventions were delivered.

\section{Analysis plan}

Qualitative and quantitative methods of analysis were used. Staff questionnaires were administered at three time points: pre training, immediately post training and then 12 weeks after the study had taken place. These questionnaires included the Shortened Alcohol and Alcohol Problems Perceptions Questionnaire $(\text { SAAPPQ })^{31}$ which is an internationally validated tool to assess professionals' role security and therapeutic commitment to working with people who drink alcohol. $^{31}$

If the behaviour change theories and methods incorporated into this evaluation are successful, SAAPPQ scores should increase across the three time points. Additional questions measuring changes to knowledge, attitudes and beliefs were also included. A $1 \mathrm{~h}$ focus group was held pre training followed by a further focus group after the 12-week study to ascertain nurses' perceived and actual barriers and facilitators implementing ASBI. All nurses consented to be audio recorded. A framework analysis ${ }^{32}$ was used as the focus group topic guide, designed around the domains of $\mathrm{TDF}^{24}$ and was deductive in approach. Themes included skills, knowledge, beliefs about capabilities and beliefs about consequences, environmental context and resources.
The AUDIT was used to screen patients to ascertain what level they were drinking at risky levels. The AUDIT can be scored between 0 and 40 and can be scored using a mean score or categorically; a score of $\geq 8$ indicates hazardous (score of 8-15) or harmful drinking (16-19) or probable dependent drinking $(\geq 20)$, with a sensitivity of $92 \%$ and specificity of $94 \% .^{33}$

Statistical analysis of anonymised AUDIT questionnaires was performed using SPSS V.19. The statistical analysis was primarily descriptive and focused on the patient flow through the project. $\chi^{2}$ tests were used to assess categorical data to determine differences in the denominator population attending the endoscopy day-unit and those accepting an AUDIT questionnaire.

\section{RESULTS}

\section{Staff questionnaires}

Thirteen nurses completed all three time-point questionnaires that were used in the analysis (tables 1 and 2). On the SAAPPQ, levels or role adequacy, role legitimacy, motivation to discuss alcohol, security in their role, job satisfaction and commitment to working with patients who drink increased during the time of the study (table 1).

Nurses identified that they had gained new knowledge, skills and confidence from taking part in the training and would recommend the training to colleagues. While most of the nurses attending training had the intention of completing the online Alcohol Learning Centre Hospital Module on ASBI, only two completed the module. Those who did, did so in their own time and found it to be useful and would recommend it to colleagues. All nurses reported that they used their new knowledge and skills during the 12-week study (table 2).

\section{Focus groups}

Before training, six nurses participated in a focus group. All were women with varying levels of endoscopy experience. After the 12-week study period, four of the six nurses participated in another focus group. The themes from the focus groups are based on the TDF domains.

Pretraining experience: In the first focus group, nurses discussed dependant drinkers as their primary experience of patients and alcohol consumption seemingly overlooking the relevance of the approach to

Table 1 SAAPPQ results

\begin{tabular}{|c|c|c|c|c|c|c|c|}
\hline Time point & $\begin{array}{l}\text { Role } \\
\text { adequacy }\end{array}$ & $\begin{array}{l}\text { Role } \\
\text { legitimacy }\end{array}$ & Motivation & $\begin{array}{l}\text { Task-specific } \\
\text { self-esteem }\end{array}$ & $\begin{array}{l}\text { Work } \\
\text { satisfaction }\end{array}$ & $\begin{array}{l}\text { Role } \\
\text { security }\end{array}$ & $\begin{array}{l}\text { Therapeutic } \\
\text { commitment }\end{array}$ \\
\hline (N13) & $\begin{array}{l}\text { Mean (SD) } \\
\text { Median }\end{array}$ & $\begin{array}{l}\text { Mean (SD) } \\
\text { Median }\end{array}$ & $\begin{array}{l}\text { Mean (SD) } \\
\text { Median }\end{array}$ & $\begin{array}{l}\text { Mean (SD) } \\
\text { Median }\end{array}$ & $\begin{array}{l}\text { Mean (SD) } \\
\text { Median }\end{array}$ & $\begin{array}{l}\text { Mean (SD) } \\
\text { Median }\end{array}$ & $\begin{array}{l}\text { Mean (SD) } \\
\text { Median }\end{array}$ \\
\hline 1-Pre training & $10(2) 10$ & $10(2) 10$ & $9(1) 9$ & $9(8) 11$ & $9(1) 8$ & $20(4) 20$ & $28(4) 29$ \\
\hline 2-Post training & $11(2) 12$ & $11(3) 12$ & $10(2) 10$ & $8(5) 10$ & $9(2) 8$ & $22(5) 24$ & 29 (3) 30 \\
\hline
\end{tabular}

SAAPPQ, Shortened Alcohol and Alcohol Problems Perceptions Questionnaire. 
Table 2 Knowledge, attitudes, values and beliefs

\begin{tabular}{|c|c|c|c|c|c|c|c|c|}
\hline \multirow{3}{*}{$\begin{array}{l}\text { Time point } \\
(n=13)\end{array}$} & $\begin{array}{l}\text { Knowledge } \\
\text { on health } \\
\text { effects of } \\
\text { alcohol }\end{array}$ & $\begin{array}{l}\text { Importance } \\
\text { of alcohol } \\
\text { screening }\end{array}$ & $\begin{array}{l}\text { Importance } \\
\text { of brief } \\
\text { intervention }\end{array}$ & $\begin{array}{l}\text { Appropriate } \\
\text { to discuss } \\
\text { AUD with } \\
\text { patients }\end{array}$ & $\begin{array}{l}\text { Confidence } \\
\text { to hold a } \\
\text { conversation }\end{array}$ & $\begin{array}{l}\text { Confidence } \\
\text { to signpost } \\
\text { to alcohol } \\
\text { services }\end{array}$ & $\begin{array}{l}\text { Feasibility } \\
\text { to include } \\
\text { ASBI into } \\
\text { routine } \\
\text { practice }\end{array}$ & $\begin{array}{l}\text { Clinical } \\
\text { environment } \\
\text { conducive to } \\
\text { ASBI }\end{array}$ \\
\hline & $\begin{array}{l}1=\text { none, } 5 \\
\text { high level }\end{array}$ & $\begin{array}{l}1=\text { not, } \\
5 \text { very }\end{array}$ & $\begin{array}{l}1=\text { not, } \\
5 \text { very }\end{array}$ & $\begin{array}{l}1=\text { not at all, } \\
5=\text { highly } \\
\text { appropriate }\end{array}$ & $\begin{array}{l}1=\text { not } \\
\text { confident, } \\
5=\text { very } \\
\text { confident }\end{array}$ & $\begin{array}{l}1=\text { not } \\
\text { confident, } \\
5=\text { very } \\
\text { confident }\end{array}$ & $\begin{array}{l}1=\text { not, } \\
5=\text { very }\end{array}$ & $\begin{array}{l}1=\text { not } \\
\text { conductive, } \\
5=\text { very } \\
\text { conductive }\end{array}$ \\
\hline & Median & Median & Median & Median & Median & Median & Median & Median \\
\hline 1-Pre training & 3 & 5 & 5 & 4 & 3 & 3 & 4 & 3 \\
\hline $\begin{array}{l}\text { 2-Post } \\
\text { training }\end{array}$ & 4 & 5 & 5 & 5 & 4 & 4 & 4 & 4 \\
\hline $\begin{array}{l}\text { 3-12 weeks } \\
\text { post study }\end{array}$ & 4 & 5 & 4 & 4 & 4 & 4 & 3 & 3 \\
\hline
\end{tabular}

ASBI, alcohol screening and brief intervention; AUD, alcohol use disorder.

addressing other patterns of risky alcohol use. 'I find the drinkers, the alcoholics, are very open about why they drink' and '“Some patients have had alcohol when they come in. You can smell it on them'. Furthermore, nurses demonstrated concern regarding commencing a potentially sensitive conversation about alcohol consumption and then not having time to deal with the outcomes of the conversation. 'They [patients] may start opening up and then you're sat there and you don't know what to do with them.' As can be seen below, these views changed by the second focus group.

Pretraining knowledge/skills: In the first focus group, nurses identified that they had a lack of knowledge on the health effects of alcohol and where to signpost a patient should they require more specific alcohol services. 'Personally, I've never had a conversation with them [patients] about alcohol. I perhaps wouldn't know where to start.'

In the follow-up focus groups, nurses reported increased knowledge to enable them to talk to patients about alcohol. There was a consensus that following the training, there was an appreciation that ASBI was not complicated and did not require specialist skills. 'The training definitely helped. For me, not knowing much about it, having that training gave me knowledge to be more aware...It made me more aware in a positive way.'

Pretraining professional role and identity: In the first focus group, there was a consensus of opinion that discussing alcohol should be part of their job description. Talking about lifestyle issues was considered important with smoking already part of the general assessment booklet. 'Its, er, just like the smoking conversation' and 'it's relevant to the test we do.' This was reinforced in the follow-up focus group. 'I think it's been a really good health promotion exercise cos I think that's what we are, we are health educators and 'You just get into the habit of doing it. It just becomes part of something that we have to do.'
Pretraining beliefs about the capabilities: In the first focus group, nurses stated that they did not have the confidence to discuss alcohol and identified a clear training need. 'Maybe with a little bit of training cos, you know, all I know is what you see on posters and just generally what you hear from people.' Confidence had increased by the second focus group. 'Having leaflets there in front of you and then the patients don't think 'Oh my God this must be unusual'. You sort of feel more comfortable' and 'I think now if someone comes in with inflammation of their stomach I can say now have you considered alcohol, whereas before I wouldn't have thought about it'.

Pretraining environmental context and resources: In the first focus group, nurses discussed time constraints to complete all mandatory paperwork and manage patient lists. Concerns were identified regarding time to deliver a brief intervention within the clinic schedule. 'We have to assess a lot of patients-up to 20 a day so it's the time really.' In the second focus group, nurses suggested that the AUDIT-C would be possible to incorporate into the general assessment form rather than the 10-item AUDIT. 'I think it's a good idea to have just three questions in the paperwork' and 'If it's incorporated into the assessment it makes it better.'

\section{Patient flow}

During the 12-week study period, 1598 individual patients were seen in the endoscopy day-unit. Of these, 1180 patients were approached (74\%). Ninety-eight per cent $(n=1128)$ completed the AUDIT questionnaire (figure 1). The number of questionnaires ranged from 54 to 122 in the 12 weeks (mean 96, SD 21.3). Of those who did record sex, 51\% $(n=557)$ were women. Ethnicity was not recorded on 57 questionnaires. Of those who did record ethnicity, 94\% $(n=1012)$ were White British. There was no statistically significant difference between the sex, age or ethnicity of the screened population compared with those who were not screened in the time frame. 


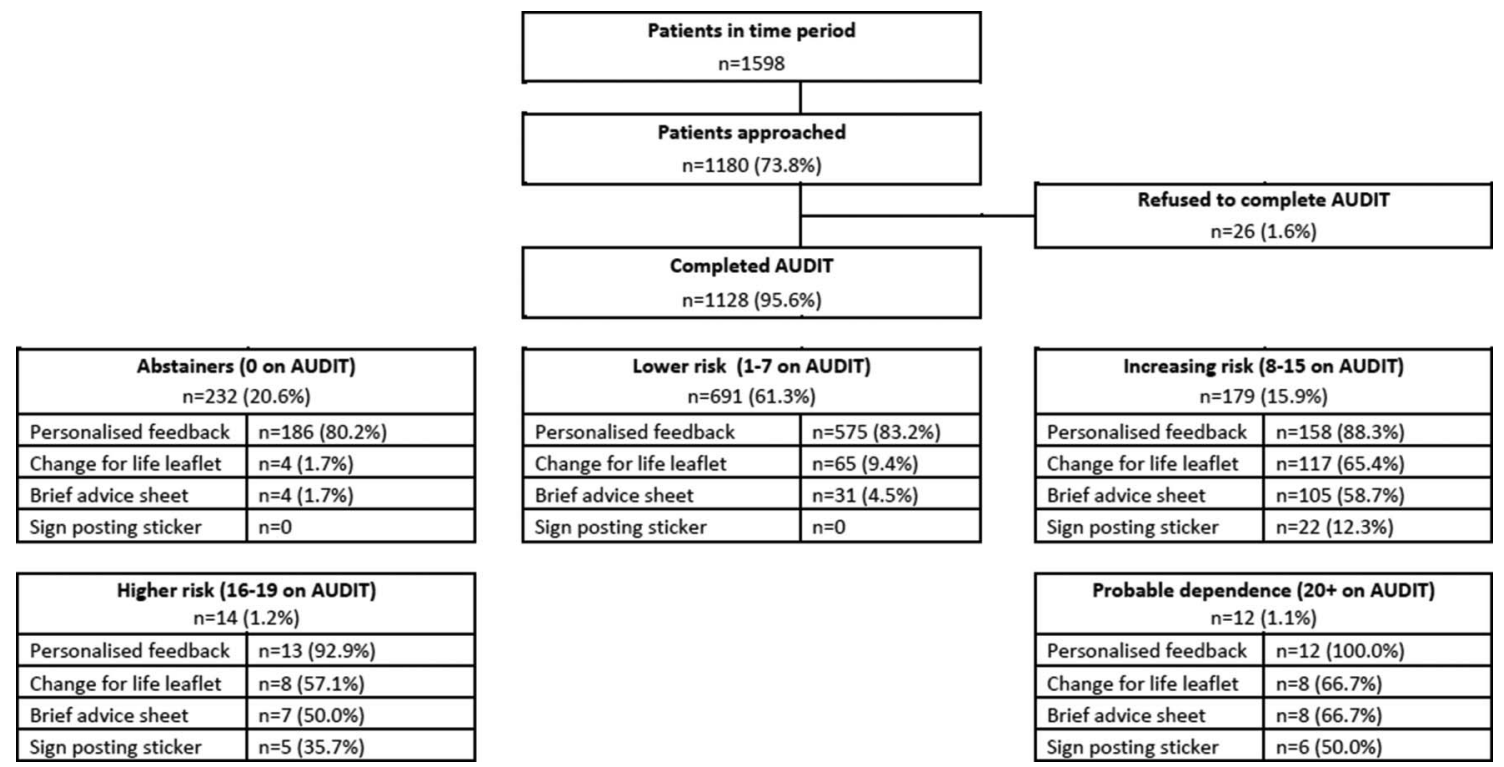

Figure 1 Flowchart of study.

\section{Alcohol Use Disorders Identification Tool}

The mean score for the AUDIT was 4.34 (SD 4.57; range $0-38)$. Eighteen per cent $(n=205)$ of patients were AUDIT positive and scored $\geq 8$ on the AUDIT. Of those where sex was recorded $(n=1093), 26 \%$ $(n=141)$ of men and $10 \%(n=57)$ of women scored AUDIT positive ( $\chi^{2} 46.49$; df $1 ; \mathrm{p}<0.0001$; table 3 ).

\section{Interventions received}

Figure 1 shows the flow of patients throughout the 12 -week study. Interventions received are shown in table 4. Eighty-four per cent $(n=945)$ of patients were recorded as receiving personalised feedback; $82 \%$ of those who were AUDIT negative and $90 \%$ of those who were AUDIT positive (table 4).

\section{DISCUSSION}

The purpose of this study was to determine how behaviour change theory and methods could impact upon the delivery of ASBI into the routine practice of a busy hospital outpatient department. The 12-week study demonstrated that opportunistic ASBI is possible in this population with staff carrying out a high proportion of screening. Seventy-two per cent of eligible patients were screened. The results show that $18 \%$ of patients screened positive on the AUDIT screening tool (score of $\geq 8$ ). A high proportion of those that should have received feedback (84\%), a leaflet $(65 \%)$ or brief advice $(59 \%)$ did so.

SAAPPQ results demonstrated a positive shift in attitudes for staff over the study period. Pre-training and post-study focus groups highlighted the barriers and facilitators in implementing ASBI. Using the TDF domains: skills, knowledge, beliefs about capabilities, beliefs about consequences, environmental context and resources were the main barriers identified in delivering ASBI as part of routine practice as others have found. ${ }^{34}$ Post-study focus group discussions highlighted a positive shift in confidence and an acknowledgement of improved skills, knowledge and perceived ability to discuss alcohol with patients.

The strengths of this study are that this is one of the first studies in a secondary care outpatient setting and showed that it is possible to implement ASBI in a busy hospital department. Others have reported that having a champion on site is imperative to work of

Table 3 AUDIT ranges by sex

\begin{tabular}{|c|c|c|c|c|c|c|}
\hline \multirow[b]{2}{*}{ Range (AUDIT score) } & \multicolumn{2}{|c|}{ Male $(n=536)$} & \multicolumn{2}{|c|}{ Female $(n=557)$} & \multicolumn{2}{|c|}{ Total $(n=1093)$} \\
\hline & $\mathbf{n}$ & Per cent & $\mathrm{n}$ & Per cent & $\mathrm{n}$ & Per cent \\
\hline Abstainers & 75 & 14.0 & 152 & 27.3 & 227 & 20.8 \\
\hline Lower risk (1-7) & 320 & 59.7 & 348 & 62.5 & 668 & 61.1 \\
\hline Increasing risk (8-15) & 124 & 23.1 & 49 & 8.8 & 173 & 15.8 \\
\hline Higher risk (16-19) & 10 & 1.9 & 3 & 0.5 & 13 & 1.2 \\
\hline Probable dependence $(\geq 20)$ & 7 & 1.3 & 5 & 0.9 & 12 & 1.1 \\
\hline
\end{tabular}

Sex not recorded for 35 patients.

AUDIT, Alcohol Use Disorders Identification Tool. 
Table 4 Interventions received according to AUDIT score of patient

\begin{tabular}{lccccc}
\hline Intervention received & Abstainer $(\mathrm{n}=232)$ & Lower risk $(\mathrm{n}=691)$ & $\begin{array}{l}\text { Increasing } \\
\text { risk }(\mathrm{n}=179)\end{array}$ & Higher risk $(\mathrm{n}=14)$ & $\begin{array}{l}\text { Probable } \\
\text { dependence }(\mathrm{n}=12)\end{array}$ \\
\hline Personalised feedback & $186(80.1 \%)$ & $575(83.2 \%)$ & $158(88.3 \%)$ & $13(92.9 \%)$ & $12(100 \%)$ \\
Change for life leaflet & $4(1.7 \%)$ & $65(9.4 \%)$ & $117(65.4 \%)$ & $8(57.1 \%)$ & $8(66.7 \%)$ \\
Brief advice sheet & $4(1.7 \%)$ & $31(4.5 \%)$ & $105(58.7 \%)$ & $7(50 \%)$ & $8(66.7 \%)$ \\
Signposting sticker & 0 & 0 & $22(12.3 \%)$ & $5(35.7 \%)$ & $6(50 \%)$ \\
\hline
\end{tabular}

Greyed out boxed indicate when intervention was given per protocol.

AUDIT, Alcohol Use Disorders Identification Tool.

this kind, ${ }^{13} 3536$ and in this present study, we did have a nurse who led the work from the inside. To aid other practitioners replicate this work, an 'Implementation Toolkit' has been developed for hospital staff which includes training materials (PowerPoint presentation and guidelines for use) and examples of ASBI tools with guidelines of how they can be adapted for different wards which was made available to all staff through the hospital intranet. The toolkit also includes links to readily available online training materials.

This study does, however, have limitations. It was conducted within one department of a single hospital based in North-East England over a very short period of time. Only a small number of staff took part in the focus groups and the questionnaires and we do not have any feedback from patients. Not all patients received the intervention that they should have and information was not recorded for a high proportion of people in relation to their intervention. One reason for this was that this was an extra piece of paper added to the existing patient assessment, which meant for some of the questions, for example, gender, the nurse was completing this information twice. The hospital has incorporated the screening tool into their assessment tool as well as information relating to whether a brief intervention took place which will mean that it is not an add-on to existing documentation which has been shown to be a barrier to staff taking part in ASBI. ${ }^{20}{ }^{21}$ Evaluation of completion of information should be a part of any key performance indicators in relation to any ongoing work, however, it may be that in this environment screening and feedback is the most that can be carried out.

\section{Conclusion}

This study has shown that it is possible to reach a high number of patients in a busy hospital out-patient department and deliver ASBI by working with staff using theoretical frameworks for training. Embedding evidence-based public health interventions into routine clinical environments is complex. The social system in which professionals operate requires consideration alongside individual professionals' real and perceived barriers and facilitators to change. By applying all three layers of the conceptual model, a process for change can be planned and delivered.

\section{Key messages}

What is already known on this topic

- In the UK, alcohol is responsible for 7\% of all hospital admissions, costing $\mathrm{f} 2.7$ billion per year.

- Alcohol Screening and Brief Interventions (ASBI) can significantly reduce hazardous and harmful drinking.

- Despite the evidence ASBI is not being routinely used in hospital departments as part of routine clinical practice.

\section{What this study adds}

- By using theoretical frameworks for nurse training it is possible to carry out high numbers of ASBI as part of routine clinical practice in an endoscopy day unit.

- Embedding screening tools into routine paperwork has the potential to increase the numbers of ASBI carried out.

Twitter Follow Dorothy Newbury-Birch at @dotbirch

Acknowledgements The authors wish to acknowledge the help of Frances Blackburn, Head of Nursing at the hospital involved and Dawn Scott who was Acting Director of Public Health in the area the research took place. The authors would also like to acknowledge Professor Richard Thomson as GO's trainee supervisor.

Contributors GO carried out the work as part of her Public Health Specialty Training and wrote the first draft of the article. DNB supervised GO during her placement and commented on the draft of the article. All authors were members of the steering group that oversaw the work and were involved in the research at all stages. All authors approved the final version of the article.

Competing interests None.

Provenance and peer review Not commissioned; externally peer reviewed.

Data sharing statement The questionnaire and further data are available from the corresponding author.

Open Access This is an Open Access article distributed in accordance with the Creative Commons Attribution Non Commercial (CC BY-NC 4.0) license, which permits others to distribute, remix, adapt, build upon this work noncommercially, and license their derivative works on different terms, provided the original work is properly cited and the use is non-commercial. See: http://creativecommons.org/licenses/by$\mathrm{nc} / 4.0 /$

\section{REFERENCES}

1 HM Government. The Government's alcohol strategy. Crown Copyright, Published in London UK, 2012. 
2 North West Public Health Observatory (NWPHO). Topography of Drinking Behaviors in England: Synthetic estimates of numbers and proportions of abstainers, lower risk, increasing risk and higher risk drinkers in Local Authorities in England. Liverpool: NWPHO, 2011.

3 Babor TF, Higgins-Biddle J, Saunders J, et al. The Alcohol Use Disorders Identification Test: Guidelines for use in primary care. Geneva, Switzerland: W.H.O. Department of Mental Health and Substance Dependence, 2001.

4 Gili-Miner M, Bejar-Prado L, Gili-Ortiz E, et al. Alcohol use disorders among surgical patients: Unplanned 30-days readmissions, length of hospital stay, excessive costs and mortality. Drug Alcohol Depend 2014;137:55-61.

5 Department of Health. Healthy lives, healthy people. Department of Health, 2010.

6 University of Stirling, Alcohol Health Alliance UK, British Liver Trust. Health first: an evidence based alcohol strategy for the UK. University of Stirling, 2013.

7 Kaner E, Bland M, Cassidy P, et al. Effectiveness of screening and brief alcohol intervention in primary care (SIPS trial): pragmatic cluster randomised controlled trial. BMJ 2013;346: e8501.

8 Kaner E, Beyer F, Dickinson H, et al. Effectiveness of brief alcohol interventions in primary care populations. Cochrane Database Syst Rev 2007;(2):CD004148.

9 National Institute for Health and Clinical Excellence. Alcoholuse disorders-preventing the development of hazardous and harmful drinking. 2010. http://guidanceniceorguk/PH24

10 Heather N. A long-standing World Health Organization collaborative project on early identification and brief alcohol intervention in primary health care comes to an end. Addiction 2007;102:679-81.

11 O'Donnell A, Anderson P, Newbury-Birch D, et al. The impact of brief alcohol interventions in primary healthcare: a systematic review of reviews. Alcohol Alcohol 2014;49:66-78.

12 McQueen J, Howe T, Allan L, et al. Brief interventions for heavy alcohol users admitted to general hospital wards. Cochrane Database Syst Rev 2011;(8):CD005191.

13 Fahy P, Croton G, Voogt S. Embedding routine alcohol screening and brief interventions in a rural general hospital. Drug Alcohol Rev 2011;30:47-54.

14 Anderson P, Braddick F, Reynolds J \& Gual A eds. (2013) Alcohol Policy in Europe: Evidence from AMPHORA. 2nd ed. The AMPHORA project.

15 Saitz R. Alcohol screening and brief intervention in primary care: Absence of evidence for efficacy in people with dependence or very heavy drinking. Drug Alcohol Rev 2010;29:631-40.

16 Drummond C, Wolstenholme A, Deluca P, et al Alcohol interventions and treatment in Europe. In: Anderson P, Braddick F, Reynolds J, Gual A, eds. Alcohol policy in Europe: evidence from AMPHORA. 2nd edn. The AMPHORA project, 2013.

17 Lock C, Kaner E, Lamont S, et al. A qualitative study of nurses' attitudes and practices regarding brief alcohol intervention in primary health care. J Adv Nurs 2002;39:333-42.

18 McAvoy BR, Donovan RJ, Jalleh G, et al. General practitioners, prevention and alcohol-a powerful cocktail? Facilitators and inhibitors of practising preventive medicine in general and early intervention for alcohol in particular: a 12-nation key informant and general practitioner study. Drugs 2001;8:103-17.
19 Wilson G, Lock C, Heather N, et al. Intervention against excessive alcohol consumption in primary health care: a survey of GPs' attitudes and practices in England ten years on. Alcohol Alcohol 2011;46:570-7.

20 Broyles L, Rodriguez K, Kraemer K, et al. A qualitative study of anticipated barriers and facilitators to the implementation of nurse-delivered alcohol screening, brief intervention, and referral to treatment for hospitalized patients in a Veterans Affairs medical centre. Addict Sci Clin Pract 2012;7:1-20.

21 Groves P, Pick S, Davis P, et al. Routine alcohol screening and brief interventions in general hospital in-patient wards: acceptability and barriers. Drugs 2010;17:55-71.

22 May C, Finch T. Implementing, embedding, and integrating practices: an outline of normalization process theory. Sociology 2009;43:535-54.

23 Michie S, Johnston M, Abraham C, et al. Making psychological theory useful for implementing evidence based practice: a consensus approach. Qual Saf Health Care 2005;14:26-33.

24 Cane J, O'Connor D, Michie S. Validation of the theoretical domains framework for use in behaviour change and implementation research. Implement Sci 2012;7:37.

25 Eccles M, Grimshaw J, Walker A, et al. Changing the behavior of healthcare professionals: the use of theory in promoting the uptake of research findings. J Clin Epidemiol 2005;58:107-12.

26 Forsetlund L, Bjorndal A, Rashidian A, et al. Continuing education meetings and workshops: effects on professional practice and health care outcomes. Cochrane Database Syst Rev 2009;(2):CD003030.

27 Baker R, Camosso-Stefanovic J, Gillies C, et al. Tailored interventions to overcome identified barriers to change: Effects on professional practice and health care outcomes. Cochrane Database Syst Rev 2010;(3):CD005470.

28 Jamtvedt G, Young J, Kristoffersen D, et al. Audit and feedback: effects on professional practice and health care outcomes. Cochrane Database Syst Rev 2010;(2):CD0004148.

29 Drummond C, Deluca P, Coulton S, et al. The effectiveness of alcohol screening and brief intervention in emergency departments: a multicentre pragmatic cluster randomized controlled trial. PLOS ONE 2014;9:e99463.

30 McAvoy B, Kaner E, Haighton K, et al. 'Drink-Less'Marketing a brief intervention package in UK general practice. Fam Pract 1997;14:427-8.

31 Anderson P, Clement S. The AAPPQ revisited: the measurement of general practitioners' attitudes to alcohol problems. Br J Addict 1987;82:753-9.

32 Pope C, Ziebland S, Mays N. Qualitative research in healthcare: analysing qualitative data. BMJ 2000;320:114-16.

33 Saunders JB, Aasland OG, Babor TF, et al. Development of the Alcohol Use Disorders Identification Test (AUDIT): WHO Collaborative Project on Early Detection of Persons with Harmful Alcohol Consumption. Addiction 1993;88:791-804.

34 Anderson P. Overview of interventions to enhance primary-care provider management of patients with substance-use disorders. Drug Alcohol Rev 2009;28:567-74.

35 Patton R, O'Hara P. Alcohol: signs of improvement. The 2nd national Emergency Department survey of alcohol identification and intervention activity. Emerg Med J 2013;30:492-5.

36 Grimshaw J, Eccles M, Lavis J, et al. Knowledge translation of research findings. Implement Sci 2012;7:50. 